\title{
Capsule Commentary on Jetelina et al., Patient-Reported Barriers to Completing a Diagnostic Colonoscopy Following Abnormal Fecal Immunochemical Test among Uninsured Patients
}

\author{
Sanja Percac-Lima, MD, MPH, PhD
}

Division of General Internal Medicine, Massachusetts General Hospital, Harvard Medical School, Boston, MA, USA.

J Gen Intern Med 34(9):1851

DOI: $10.1007 / \mathrm{s} 11606-019-05148-7$

(c) Society of General Internal Medicine 2019

J etelina et al. describe barriers to completing a diagnostic colonoscopy after an abnormal fecal immunochemical test (FIT) in patients receiving care in North Texas safety-net health system. ${ }^{1}$

This study revealed that for many uninsured/underinsured patients, CRC screening with FIT might not be effective. Although all insurances are obligated to cover recommended cancer screening test, ${ }^{2}$ if FIT is positive, colonoscopy would be considered diagnostic test and underinsured patients could be faced with bills that might be as high as their monthly wages. As a result, although aware of possible consequences, underserved low-income patients refuse the procedure. For some underinsured patients, colonoscopy might be a more appropriate first-line CRC screening option.

Over a third of the patients had comorbidities, even reported that their physicians advised them not to have the procedure. In the current system, primary care physicians are often pressed to improve cancer-screening rates and rely on their staff and population mangers to mail stool cards to patients. Ideally, patients' records would be screened for co-morbidities or shared decisionmaking regarding CRC screening performed prior to FIT distribution. Unfortunately, due to many priorities, multiple required quality measures, and less time, primary care physicians often might not have time to discuss these issues with their patients.

Many of the patients reported significant social barriers such as unreliable transportation, person to accompany them, time from work, childcare, and fears and concerns about procedure which are almost identical to patients' reported barriers to screening colonoscopy. ${ }^{3}$ Studies have shown that patient navigators can effectively overcome these barriers. ${ }^{4}$ Similar patient navigation programs could help underserved patient receive follow-up colonoscopy post abnormal FIT test.

Published online July 10, 2019
One of the limitations of this study is that $42 \%$ of patients who failed to complete colonoscopy did not report barriers. Patients could not be reached so many salient barriers might not have been recorded. Further studies are needed to explore barriers to follow-up abnormal CRC screening for most of these underserved patients so interventions could be developed and implemented ${ }^{5}$ to ensure equity in colorectal cancer prevention and early detection.

Corresponding Author: Sanja Percac-Lima, MD, MPH, PhD; Division of General Internal Medicine, Massachusetts General Hospital, Harvard Medical School, Boston, MA, USA (e-mail: spercaclima@mgh.harvard.edu).

\section{REFERENCES}

1. Jetelina KK, Yudkin JS, Miller S, Berry E, Lieberman AJ, Gupta S, Balasubramanian BA. Patient-reported barriers to completing a diagnostic colonoscopy following abnormal fecal immunochemical test among uninsured patients. J Gen Intern Med https://doi.org/10.1007/s11606-01905117-0.

2. US Preventive Services Task Force, Bibbins-Domingo K, Grossman DC, Curry SJ, Davidson KW, Epling JW Jr, Garcia FAR, Gillman MW, Harper DM, Kemper AR, Krist AH, Kurth AE, Landefeld CS, Mangione CM, Owens DK, Phillips WR, Phipps MG, Pignone MP, Siu AL. Screening for colorectal cancer: US Preventive Services Task Force recommendation statement. JAMA. 2016;315(23):2564-2575. https://doi.org/10.1001/ jama.2016.5989.

3. Green AR, Peters-Lewis A, Percac-Lima S, Betancourt JR, Richter JM, Janairo MP, Gamba GB, Atlas SJ. Barriers to screening colonoscopy for low-income Latino and white patients in an urban community health center. J Gen Intern Med 2008;23(6):834-40. https://doi.org/10.1007/ s11606-008-0572-6.

4. Dougherty MK, Brenner AT, Crockett SD, Gupta S, Wheeler SB, CokerSchwimmer M, Cubillos L, Malo T, Reuland DS. Evaluation of interventions intended to increase colorectal cancer screening rates in the United States: a systematic review and meta-analysis. JAMA Intern Med 2018;178(12):1645-1658. https://doi.org/10.1001/jamainternmed.2018. 4637.

5. Selby K, Baumgartner C, Levin TR, Doubeni CA, Zauber AG, Schottinger J, Jensen CD, Lee JK, Corley DA. Interventions to improve follow-up of positive results on fecal blood tests: a systematic review. Ann Intern Med. 2017;167(8):565-575. https:// doi.org/10.7326/M17-1361.

Publisher's Note Springer Nature remains neutral with regard to jurisdictional claims in published maps and institutional affiliations. 